\title{
O DIREITO À DIVERSIDADE DAS COMUNIDADES INDÍGENAS. MULTICULTURALISMO, DIREITO À VIDA E INFANTICÍDIO
}

\author{
MARCOS AUGUSTO MALISKA ${ }^{1}$ \\ JEDERSON SUZIN ${ }^{2}$
}

\begin{abstract}
RESUMO: A compreensão acerca do multiculturalismo, tido basicamente como a possibilidade da existência e co-existência de uma multiplicidade de traços culturais dentro ou além de um Estado-Nação, bem como a atenção para a necessidade da existência de uma política de reconhecimento público das diferenças como condição de sobrevivência das sociedades multiculturais, apresentam-se como desafios para a Constituição Federal de 1988. Igualmente merece atenção o problema decorrente do conflito entre os valores arraigados em algumas comunidades indígenas, especificamente o infanticídio, gerados pelas diferentes formas de compreensão destas comunidades em relação ao que seja "humano" ou "nascimento", e outros valores aceitos como universais, como a proteção da vida, fato este a externar uma tensão cultural e jurídica. Por fim, mas não menos importante, apresenta-se o meio termo entre relativismo e universalismo cultural no sentido de que além de se admitir a existência de valores absolutos mínimos, igualmente importante é o diálogo intercultural. PALAVRAS-CHAVE: Multiculturalismo; Constituição Federal Brasileira; Infanticídio em Comunidades Indígenas; Diálogo Cultural.
\end{abstract}

ABSTRACT: Coming from an understanding about the multiculturalism, which is had basically as the possibility of existence and co-existence of a multiplicity of cultural traits inside or beyond a Nation-State and attracting attention to the necessity of the existence of a policy of public recognition of the differences as surviving condition of the multicultural societies, it will try to retrieve the treatment given by the Federal Constitution of 1988 to this social reality, all that based on the analysis of some of its devices. Continual act, it will be analysed the problem derived from the conflict among permanent values in some Indian communities, specifically the infanticide, created by the different way of understanding of these communities in relation to it is "human" or what it is "birth", with other values accepted as universal, like the life protection, this fact utters a

Artigo recebido em 07.06.2011. Pareceres emitidos em 12.07.2011 e 17.07.2011.

Artigo aceito para publicação em 05.09.2011.

${ }^{1}$ Professor do Programa de Mestrado em Direitos Fundamentais e Democracia das Faculdades Integradas do Brasil, UniBrasil, em Curitiba, Estado do Paraná, Brasil. Procurador Federal. marcosmaliska@yahoo.com.br

2 Juiz de Direito do Estado do Paraná. Mestrando em Direitos Fundamentais e Democracia nas Faculdades Integradas do Brasil, UniBrasil, em Curitiba, Estado do Paraná, Brasil. jedersonsuzin@gmail.com 
cultural and juridical tension. At last and adopting a compromise between the relativism and the cultural universalism, as long as admitting the existence of minimal absolute values, it will be proposed an intercultural dialog.

KEYWORDS: Multicuturalism; Brazilian Federal Constitution; Infanticide in Indian Communities; Intercultural Dialog.

SUMÁRIO: Introdução; 1. Compreendendo o Multiculturalismo; 2. A Carta Constitucional e o Tratamento Conferido à Diversidade Cultural; 3. Multiculturalismo, Direito à Vida e Infanticídio em Comunidades Indígenas; Referências Bibliográficas.

SUMMARY: Introduction; 1 . Understanding Multiculturalism; 2 . The Constitutional Charter and the Treatment Given to Cultural Diversity; 3. Multiculturalism, Right to Life and Infanticide in Indian Communities; References.

\section{INTRODUÇÃO}

O direito constitucional tem sido palco de disputas as mais variadas. A constitucionalização da vida política trouxe para esse ramo do conhecimento jurídico a difícil tarefa de conjugar os mais variados direitos protegidos no texto constitucional. O tema objeto do presente artigo se enquadra perfeitamente nessa difícil tarefa.

O presente texto traz uma discussão sobre multiculturalismo no contexto da prática cultural indígena do infanticídio. ${ }^{3}$ Para isso, inicialmente, o texto procura compreender o(s) sentido(s) de multiculturalismo, para em seguida analisá-lo(s) no contexto da Constituição de 1988. Trata-se de um estudo interdisciplinar que transita desde a sociologia, passando pela filosofia política e o direito constitucional. Por fim é abordado o tema do infanticídio indígena propriamente.

O estudo não tem a pretensão de explorar o assunto de forma aprofundada. Em síntese, ele procura balizar a prática jurídica quando da existência de conflitos dessa natureza. A forma de tratamento de questões envolvendo o assunto aqui em discussão pode variar significativamente tendo em vista o caso concreto a ser analisado.

\section{COMPREENDENDO O MULTICULTURALISMO}

Sendo a República Federativa do Brasil um Estado pluralista apresenta-se como irrefutável a imposição da necessidade de se adotar, como fator legitimante, a compatibilização de seus atos com a diversidade inerente às comunidades multiculturais. Por isso é que tal constatação leva à necessidade de compreendermos o significado atual do conceito "multiculturalismo".

Segundo Santos, paralelamente a uma concepção de multiculturalismo como projeto político, também se reconhece o multiculturalismo, num sentido

\footnotetext{
${ }^{3} \mathrm{O}$ tema infanticídio está sendo usado aqui sem precisão jurídica técnica e ainda é passível de críticas, visto que o seu significado de certa forma implica um olhar sobre uma prática cultural a partir de uma outra perspectiva, ou seja, talvez se devesse buscar um outro termo para designar esse "acontecimento" que leva as crianças à morte.
} 
descritivo, como a existência de uma multiplicidade de culturas no mundo; como a co-existência de culturas diversas no espaço de um mesmo Estado-nação e, ainda, como a existência de culturas que se interinfluenciam tanto dentro como além do Estado-nação, vale dizer, expressaria 0 multiculturalismo, segundo referido autor, a possibilidade de convivência de grupos com diferentes traços culturais dentro ou além dos limites territoriais de um Estado-nação. ${ }^{4}$

Assim, inerente ao conceito de multiculturalismo está a ideia do "plural", do "diferente", portanto, a necessidade de poder num mundo globalizante que tende a flexibilizar a intransponibilidade das fronteiras territoriais à bem de uma hegemonização capitalista, bem como ofertar condições abrigadoras da convivência solidária e harmônica dos iguais e dos diferentes.

Ocorre que é justamente deste multiculturalismo enquanto projeto de harmonização coletiva que se sobressaem as tensões da modernidade, as quais, marcadas por uma incompreensão histórica, fruto de uma reconhecida hegemonia cultural eurocêntrica, resistem à implantação de políticas afirmativas neutralizadoras do processo de exclusão do "diferente". 5

Neste sentido, uma vez que a construção social da identidade ocorre em contextos marcados por relações de poder, propõe Castells três formas e origens de construção de identidades: (i) a identidade legitimadora, introduzida pelas instituições dominantes da sociedade no intuito de expandir e racionalizar sua dominação; (ii) a identidade de resistência, criada por atores que se encontram em posições/condições desvalorizadas e/ou estigmatizadas pela lógica da dominação, construindo, assim, trincheiras de resistência e sobrevivência com base em princípios diferentes dos que permeiam as instituições da sociedade; e (iii) a identidade de projeto, quando atores sociais, utilizando-se de qualquer tipo material cultural ao seu alcance, constroem uma nova identidade capaz de redefinir sua posição na sociedade e, ao fazê-lo, de buscar a transformação de toda a estrutura social. $^{6}$

Hall, por outro lado, partindo da concepção do indivíduo, apresenta três ideias de identidade: (i) do sujeito do Iluminismo, "baseado numa concepção

\footnotetext{
4 SANTOS, Boaventura de Souza (Org.). Reconhecer para Libertar. Os Caminhos do Cosmopolitismo Multicultural. Rio de Janeiro: Civilização Brasileira. 2003, p. 28.

${ }^{5}$ Casals aponta para a necessidade de superação da desigualdade estrutural por meio de políticas afirmativas inclusivas das minorias excluídas: "os direitos dos grupos se justificam como limites temporais ao princípio geral da homogeneidade dos direitos, com o objetivo de superar a situação de injustiça estrutural". CASALS, Neus Torbisco. La institucionalización de La diferencia: algunas notas sobre desigualdad estructural y democracia. In. SABA, Roberto. (Org.) Los Límites de la Democracia. Buenos Aires: Del Puerto, 2005, p. 44. Sobre a necessidade do resgate do ideal revolucionário da promoção da igualdade nos Estados Unidos, ver BALKIN, Jack M. e SIEGEL, Reva B. Remembering How to Do Equality. In. BALKIN, Jack M. e SIEGEL, Reva B. The Constitution in 2020. New York: Oxford University Press, 2009, p. 93 e seg. ${ }^{6}$ CASTELLS, Manuel. O Poder da Identidade - A Era da Informação. Economia, Sociedade e Cultural. Vol. 2. Trad. Klauss Brandini Gerhardt. São Paulo: Paz e Terra, 2008, p. 24.
} 
da pessoa humana como um indivíduo totalmente centrado, unificado, dotado das capacidades de razão, de consciência e de ação, cujo 'centro' consistia num núcleo interior (...). O centro essencial do eu era a identidade de uma pessoa"; (ii) do sujeito sociológico, que "refletia a crescente complexidade do mundo moderno e a consciência de que este núcleo interior do sujeito não era autônomo e auto-suficiente, mas formado na relação com outras pessoas importantes para ele, que mediavam para o sujeito os valores, sentidos e símbolos - a cultura - dos mundos que ele/ela habitava. (...) De acordo com essa visão (...) a identidade é formada na interação entre o eu e a sociedade"; (iii) do sujeito pós-moderno, no qual "o sujeito, previamente vivido como tendo uma identidade unificada e estável, está se tornando fragmentado; composto não de uma única, mas de várias identidades, algumas vezes contraditórias ou não resolvidas. (...) Esse processo produz o sujeito pós-moderno, conceptualizado como não tendo uma identidade fixa, essencial ou permanente. A identidade torna-se uma celebração móvel; formada e transformada continuamente em relação às formas pelas quais somos representados ou interpelados nos sistemas culturais que nos rodeiam. É definida historicamente, e não biologicamente. $O$ sujeito assume identidades diferentes em diferentes momentos, identidades que não são unificadas ao redor de um eu coerente". ${ }^{7}$

Acerca da temática identidade/diferença, Taylor chama a atenção para a necessidade da existência de uma política de reconhecimento público das diferenças como condição de sobrevivência das sociedades multiculturais, isso em razão da relação existente entre reconhecimento e identidade, esta tida como a forma de definição da pessoa, a partir de suas características fundamentais, que a torna um ser humano ${ }^{8}$. Segundo o autor, "a tese consiste no fato de a nossa identidade ser formada, em parte, pela existência ou inexistência de reconhecimento e, muitas vezes, pelo reconhecimento incorreto dos outros, podendo uma pessoa ou grupo de pessoas serem realmente prejudicadas, serem alvos de uma verdadeira distorção, se aqueles que os rodeiam refletirem uma imagem limitativa, de inferioridade ou de desprezo por eles mesmos. O não reconhecimento ou o reconhecimento incorreto podem afetar negativamente, podem ser uma forma de agressão, reduzindo a pessoa a uma maneira de ser falsa, distorcida, que a restringe"

De se concluir, segundo exposto pelo autor, pela existência de um nexo etiológico entre reconhecimento, enquanto fator exógeno, e o processo de formação de identidade individual, enquanto fator endógeno. Este estaria a tal ponto marcado por aqueles fatores externos - de exclusão - que gerariam

\footnotetext{
${ }^{7}$ HALL, Stuart. A Identidade Cultural na Pós-modernidade. Trad. Tomaz T. da Silva e Guacira L. Louro. 11. ed., Rio de Janeiro: DP\&A, 2006, p. 10-13.

8 TAYLOR, Charles. Multiculturalismo. Examinando a Política de Reconhecimento. Lisboa: Instituto Piaget, 1998, p.45-94.

${ }^{9}$ TAYLOR, Charles. Multiculturalismo, p. 45.
} 
uma auto-depreciação que viria a representar um dos instrumentos mais poderosos da sua própria opressão ${ }^{10}$.

Igualmente pondera Taylor que "perante estas considerações, o reconhecimento incorreto não implica só uma falta do respeito devido. Pode também marcar as suas vítimas de forma cruel, subjugando-as através de um sentimento incapacitante de ódio contra elas mesmas. Por isso, o respeito devido não é um ato de gentileza para com os outros. É uma necessidade vital". ${ }^{11}$

Desta forma, longe de a importância do tema residir em meras discussões acadêmicas, o multiculturalismo deve erigir-se como temática prioritária para Estados que tenham como princípio fundante a dignidade do ser humano. Isso porque não se pode conceber uma existência digna com a supressão da identidade própria do indivíduo ou, o que é muito comum, a sua submissão a um padrão cultural hegemônico.

\section{A CARTA CONSTITUCIONAL E O TRATAMENTO CONFERIDO À} DIVERSIDADE CULTURAL

A melhor maneira de extrairmos o elemento característico de uma determinada sociedade e, principalmente, a forma como tal sociedade é tratada pelo poder público é examinarmos os preceitos constitucionais que a regem. Nestes preceitos é que se conterá o regramento estrutural do Estado, seja quanto ao próprio poder, com a fixação de suas competências e limites, seja quanto aos direitos da pessoa humana.

De se acrescentar, ainda, que na compreensão de uma Constituição, o processo dialógico com a realidade social é imprescindível, como forma de revesti-la do necessário sentido axiológico. É por isso que Silva afirma que “(....) o sentido jurídico de constituição não se obterá, se a apreciarmos desgarrada da totalidade da vida social, sem conexão com o conjunto da comunidade. Pois bem, certos modos de agir em sociedade transformam-se em condutas humanas valoradas historicamente e constituem-se em fundamento do existir comunitário, formando os elementos constitucionais do grupo social, que o constituinte intui e revela como preceitos normativos fundamentais: a constituição"12.

\footnotetext{
${ }^{10}$ Interessante referência faz aqui Taylor à situação enfrentada pelas feministas e pelos negros. Segundo ele "(...) algumas feministas afirmaram que, nas sociedades patriarcais, as mulheres eram induzidas a adotar uma opinião depreciativa delas próprias. Interiorizaram uma imagem da sua inferioridade, de tal maneira que, quando determinados obstáculos reais à sua prosperidade desapareciam, elas chegavam a demonstrar uma incapacidade de aproveitarem as novas oportunidades. E, além disso, estavam condenadas a sofrer pela sua debilitada auto-estima. Também surgiram argumentos semelhantes em relação aos negros: que a sociedade branca projetou durante gerações uma imagem de inferioridade da raça negra, imagem essa que algum dos seus membros acabaram por adotar". TAYLOR, Charles. Multiculturalismo, p. 46.

11 TAYLOR, Charles. Multiculturalismo, p. 46.

12 SILVA, José Afonso da. Curso de Direito Constitucional. São Paulo: Editora Revista dos Tribunais, 1991, p. 39.
} 
Não há barreiras entre a realidade social e a Constituição. Ao contrário, o inter-relacionamento é condição necessária tanto à formação desta como a compreensão daquela. ${ }^{13} \mathrm{O}$ fim da Constituição é "a realização dos valores que apontam para o existir da comunidade". ${ }^{14}$

Assim, se o Brasil, como já antes afirmado, é composto de uma realidade marcada por uma ampla diversidade cultural, resta então perquirir, dado a limitação temática deste estudo, se esta complexidade pluralista foi incorporada na Constituição e, se foi, como tem sido a forma com que tem sido tratada.

Neste sentido, estudando o processo constituinte de 1987/1988, Pacheco escreve que a Constituinte tornou-se "um espaço de compreensão da sociedade brasileira; e compreensão de sua História e de suas questões sociais, no sentido mais amplo; de compreensão de seus valores, materiais e imateriais; enfim, de sua cultura ou, melhor dito, de sua multiculturalidade" ${ }^{\not 15}$. Segundo ainda o autor, "os segmentos mais mobilizados da sociedade puderam atuar diretamente no processo constituinte. É muito interessante observar, através da leitura de Atas dessas reuniões e audiências públicas, o nível da participação popular, principalmente no que diz respeito à questão dos direitos étnicos, objeto de nosso trabalho de pesquisa. Somente na Subcomissão de Negros, Índios e Minorias, foram dezesseis reuniões, ocorridas entre os dias 07 de abril, a primeira delas, e o dia 25 de maio de 1987, quando essa Subcomissão apresentou o seu Relatório Final. Algumas dessas reuniões e audiências se estenderam durante todo o dia, devido ao grande número de demandas por participação". ${ }^{16}$

A discussão constituinte acabou por influenciar fortemente o texto da Constituição, a começar pelo seu preâmbulo: "Nós, representantes do povo brasileiro, reunidos em Assembleia Nacional Constituinte para instituir um Estado Democrático, destinado a assegurar o exercício dos direitos sociais e individuais, a liberdade, a segurança, o bem-estar, o desenvolvimento, a igualdade e a justiça como valores supremos de uma sociedade fraterna,

\footnotetext{
${ }^{13}$ Sob o ponto de vista da hermenêutica constitucional de Friedrich Müller o processo de concretização da norma constitucional ocorre em duas fases. A primeira fase corresponde à interpretação do texto da norma, que pode ser realizado pelos métodos tradicionais de interpretação (gramatical, histórico e sistemático), como também pelos modernos procedimentos de interpretação da Constituição, por exemplo, a "interpretação conforme a Constituição", "correção funcional", "proporcionalidade", "concordância prática". O resultado dessa interpretação ele chama de programa da norma. A segunda fase envolve os dados reais do caso concreto (econômicos, políticos, sociais, técnicos). À medida que esses fatos são a) relevantes para a questão de direito em epígrafe e b) compatíveis com o programa da norma elaborado, eles constituem a segunda parte integrante da norma jurídica, a área da norma. Assim a norma jurídica acabada, construída pelo jurista consiste do programa da norma e da área da norma. MÜLLER, Friedrich. Métodos de Trabalho do Direito Constitucional. 3. ed., Rio de Janeiro: Renovar, 2005.

${ }^{14}$ SILVA, José Afonso da. Curso de Direito Constitucional, p. 39

15 PACHECO, Marcos Antônio B. Estado Multicultural e Direitos Humanos. Tópica Constitucional dos Direitos Étnicos. São Luis: UFMA/CNPq, 2005, p. 93.

${ }^{16}$ PACHECO, Marcos Antônio B. Estado Multicultural e Direitos Humanos, p. 97.
} 
pluralista e sem preconceitos, fundada na harmonia social e comprometida, na ordem interna e internacional, com a solução pacífica das controvérsias, promulgamos, sob a proteção de Deus, a seguinte Constituição da República Federativa do Brasil".

Tendo o preâmbulo como uma expressão de propósitos, princípios e sínteses de pensamentos dominantes à época da promulgação da Constituição ${ }^{17}$, porém sem adentrar aqui na discussão doutrinária existente acerca do seu valor e eficácia normativa, não há como negar que toda expressão linguística contida na Constituição tem uma legítima razão que a justifica, de modo que temerário se mostra ignorar o sentido teleológico do referido texto. Portanto, aceitando um mínimo de eficácia a ele - ainda que somente para fins de norte interpretativo de todo o sistema constitucional ${ }^{18}$ forçoso se faz concluir que o poder constituinte, reconhecendo o Brasil como uma sociedade fraterna, pluralista, sem preconceitos e fundada na harmonia social, prescreveu ao Estado uma ação diretiva voltada à efetiva garantia de certos valores tidos como superiores pela sociedade que o compõe.

Induvidoso está, pois, o reconhecimento do Brasil como representativo de uma sociedade pluralista, fraterna e sem preconceitos, do que se deduz, como inexorável corolário, a aceitação de uma pluralidade étnico-cultural que estaria entrelaçada pelos elos da fraternidade e tolerância.

O reconhecimento do "plural", do "ser diferente", faz tornar obrigação de todos - notadamente do poder público - o respeito à pessoa humana em sua particular forma de existir. O valor da identidade individualizada, expressão empregada por Taylor $^{19}$, então, passa a sobrepor-se aos padrões culturais hegemônicos.

Insta dizer, ainda, que ingrediente fundamental para a efetivação deste reconhecimento é a tolerância. Não num sentido passivo de mera resignação a um sistema opressor e chancelador de desigualdades, mas, como sugere Cardoso, indicativo de uma atitude de reconhecimento do outro como ele é e de respeito mútuo às diferenças; da capacidade de diálogo entre ideias e valores diferentes; do respeito aos direitos universais inalienáveis da pessoa

\footnotetext{
17 SILVA, José Afonso da. Comentários Contextual à Constituição. São Paulo: Malheiros Editores, 2008, p. 21.

${ }^{18}$ Segundo José Afonso da Silva “(...) os Preâmbulos valem como orientação para a interpretação e aplicação das normas constitucionais. Têm, pois, eficácia interpretativa e integrativa; mas se contém uma declaração de direitos políticos e sociais do homem, valem como regra de princípio se no texto articulado da Constituição não houver norma que os confirme eficazmente. Se houver, a eficácia da norma será aquela ditada pelo conteúdo do dispositivo que a contenha (...)"(In Comentários Contextual a Constituição., p. 22). Para Celso Ribeiro Bastos e Ives Gandra Martins, ainda que não reconheçam nele força coercitiva, admitem a sua relevância como elemento interpretativo e integrativo. BASTOS, Celso Ribeiro e MARTINS, Ives Gandra. Comentários à Constituição do Brasil. $1^{\circ}$ Vol. São Paulo: Saraiva, 1988, p. 409.

${ }^{19}$ Para Taylor, identidade individualizada é aquela que "é especificamente minha, aquela que eu descubro em mil. Esta noção surge juntamente com um ideal: o de se verdadeiro para comigo mesmo e para com a minha maneira própria de ser. (...). TAYLOR, Charles. Multiculturalismo, p. 48.
} 
humana; do reconhecimento da diversidade cultural e da resistência à opressão e desigualdade social e de uma atitude de solidariedade entre os seres humanos. ${ }^{20}$

Aliás, o Supremo Tribunal Federal, em decisão do Ministro Gilmar Mendes na Medida Cautelar em Arguição de Descumprimento de Preceito Fundamental, bem afirmou que "no limiar deste século XXI, liberdade e igualdade devem ser (re) pensadas segundo o valor fundamental da fraternidade. Com isso quero dizer que a fraternidade pode constituir a chave por meio da qual podemos abrir várias portas para a solução dos principais problemas hoje vividos pela humanidade em tema de liberdade e igualdade". Mais adiante complementa: "pensar a igualdade segundo o valor da fraternidade significa ter em mente as diferenças e as particularidades humanas em todos os seus aspectos. A tolerância em tema de igualdade, nesse sentido, impõe a igual consideração do outro em suas peculiaridades e idiossincrasias. Numa sociedade marcada pelo pluralismo, a igualdade só pode ser igualdade com igual respeito às diferenças. Enfim, no Estado democrático, a conjugação dos valores da igualdade e da fraternidade expressa uma normatividade constitucional no sentido de reconhecimento e proteção das minorias". ${ }^{21}$

Para Habermas deve-se defender uma moral assentada na igualdade de todos e na geral responsabilidade solidária de um para com o outro. A desconfiança pós-moderna acerca de um universalismo assimilador e igualitário descomprometido com o passado não compreende o sentido dessa moral e faz desaparecer o zelo pelo entrelaçamento de toda estrutura relacional de alteridade e diferença, que um universalismo bem compreendido traz. ${ }^{22}$

Passando agora ao Título I da Constituição, que trata dos Princípios Fundamentais $^{23}$, reza o art. $1^{\circ}$ que a República Federativa do Brasil constitui-se

\footnotetext{
${ }^{20}$ CARDOSO, Clodoaldo Meneguello. Tolerância e seus limites - Um olhar latino americano sobre a diversidade e desigualdade. São Paulo: Unesp, 2003, p. 146/147.

${ }^{21}$ Medida Cautelar em Arguição de Descumprimento de Preceito Fundamental 186-2 - Distrito Federal - 31/07/2009. Sobre como as Cortes Constitucionais devem lidar com os direitos das minorias, ver o interessante estudo de APPIO, Eduardo. Direito das Minorias. São Paulo: RT, 2009. A jurisprudência da Suprema Corte dos Estados Unidos da América é rica em casos envolvendo proteção das minorias, como, entre outras: Batson v. Kentucky de 1986, no qual se discutiu a exclusão de jurados negros em processo envolvendo réu negro; o clássico Brown $v$. Board of Education of Topeka, Kansas de 1954-1955, no qual se discutiu a segregação racial nas Escolas; Equal Employment Opportunity Commission (EEOC) v. Wyoming et al. de 1983, no qual se discutiu a discriminação por idade no contexto da repartição de competências do federalismo americano; Gratz v. Bollinger e Grutter v. Bollinger, ambos de 2003, nos quais se rediscutiu o tema das ações afirmativas nas Universidades: a Corte manteve o entendimento da consideração da raça como critério de admissão, no entanto apontou para a conjugação desse critério com o do desempenho individual. Ver: HARTMAN, Gary e outros (Orgs.) Landmark Supreme Court Cases. The Most Influential Decisions of the Supreme Court of the United States. New York: Facts on File Inc., 2004.

${ }^{22}$ HABERMAS, Jürgen. Die Einbeziehung des Anderen. Frankfurt am Main: Suhrkamp, 1999, p. 7.

${ }^{23}$ Importante observação aqui é feita por J. J. Gomes Canotilho e Vital Moreira, citado por Afonso de Silva em Comentários Contextual a Constituição (p. 29) de que os artigos integrantes destes princípios constitucionais fundamentais "constituem por assim dizer a síntese ou matriz
} 
em Estado Democrático de Direito e tem como fundamento a soberania, a cidadania, a dignidade da pessoa humana, os valores sociais do trabalho e da livre iniciativa e o pluralismo político.

O primeiro ponto que chama a atenção é o fato do Brasil constituir-se num Estado Democrático de Direito. Tal formato, segundo Novaes, somente ocorrerá quando tivermos um Estado "vinculado e limitado juridicamente em ordem à proteção, garantia e realização efetiva dos direitos fundamentais, que surgem como indisponíveis perante os detentores do poder e o próprio Estado". ${ }^{24}$

De se perceber, assim, que ao implantar tal formato de Estado a mera exigência do reconhecimento dos direitos fundamentais não se mostra suficiente. Exige-se mais. Exige-se a plena realização dos mesmos.

Dentre os fundamentos do Estado acima nominados, chama atenção, dado o norte deste estudo, para a cidadania, a dignidade da pessoa humana e o pluralismo político.

A cidadania, sob uma perspectiva multiculturalista e dentro da lógica defendida por Taylor, é aquela que envolve uma noção de cidadão sem formato pré-definido e imposto por uma ordem regradora, mas ao contrário, um cidadão que impõe a esta ordem o respeito à sua individualidade. É, assim, uma visão de cidadania que "(...) prima pelo bem estar dos diferentes grupos, diante da conjugação dos direitos fundamentais, que apresentam caráter individual com os direitos de caráter coletivo que levam em conta as particularidades culturais dos grupos, sendo ambos exercidos dentro dos limites territoriais e ideológicos do Estado". ${ }^{25}$

E mais, esta nova concepção de cidadania consiste, segundo Silva, "na consciência de pertinência à sociedade estatal como titular dos direitos fundamentais, da dignidade como pessoa humana, na integração participativa no processo do poder, com a igual consciência de que essa situação subjetiva envolve deveres de respeito à dignidade do outro, de contribuir para o aperfeiçoamento de todos". ${ }^{26}$

A noção de cidadão, portanto, envolve uma relação dialógica marcada pelo respeito mútuo e aceitação de individualidades, enquanto elemento da dignidade.

de todas as restantes normas constitucionais, que àquelas podem ser direta ou indiretamente reconduzidas". Para Sarlet, mediante a consagração destes princípios, "o Constituinte deixou transparecer de forma clara e inequívoca a sua intenção de outorgar aos princípios fundamentais a qualidade de normas embasadoras e informativas de toda a onde constitucional, inclusive dos direitos fundamentais, que também integram aqui o que se pode denominar de núcleo essencial da Constituição material". SARLET, Ingo Wolfgang. A Eficácia dos Direitos Fundamentais. 9. ed., Porto Alegre: Livraria do Advogado, 2008, p. 109.

${ }^{24}$ NOVAIS, Jorge Reis. Contributo para uma teoria do Estado de Direito: do Estado de Direito liberal ao Estado social e democrático de Direito. Coimbra: Almedina. 2006. p. 26.

${ }^{25}$ SLVA, Larissa Tenfen. O Multiculturalismo e a Política de Reconhecimento de Charles Taylor. NEJ - Vol. 11, n 2, p. 313-322, jul./dez. 2006.

${ }^{26}$ SILVA, José Afonso da. Comentários Contextual à Constituição, p. 36. 
Não sendo a pretensão esmiuçar o conceito de dignidade da pessoa humana, por fugir aos propósitos do presente estudo, não há como deixar de expor, ainda que sinteticamente, sua ideia base, mormente porque íntima relação possui com o tema ora abordado. Para este fim, relevante a anotação feita por Sarlet: "o que se percebe, em última análise, é que onde não houver respeito pela vida e pela integridade física do ser humano, onde as condições mínimas para uma existência digna não forem asseguradas, onde a intimidade e identidade do indivíduo forem objeto de ingerências indevidas, onde sua igualdade relativamente aos demais não for garantida, bem como onde não houver limitação do poder, não haverá espaço para a dignidade da pessoa humana, e esta não passará de mero objeto de arbítrio e injustiças. A concepção do homem-objeto, como visto, constitui justamente a antítese da noção da dignidade da pessoa humana". ${ }^{27}$

Desta clara explicação, nota-se a estreita vinculação entre dignidade da pessoa humana e o respeito à sua identidade. Não haveria, em outros termos, preservação da dignidade da pessoa humana com a supressão da identidade própria. A identidade passa, então, a se constituir em valor protegido constitucionalmente.

Acerca do pluralismo político, reforça-se agora o que já se disse ao abordar o preâmbulo da Constituição. Com ele "(....) quer realizar-se como princípio da democracia de poder aberto, estabelecendo o liame entre a liberdade e a multiplicidade dos meios de vida, não apenas como uma nova maneira de afirmar a liberdade de opinião ou de crença, mas como um sistema que enraíza esta liberdade na estrutura social". ${ }^{28}$

$\mathrm{O}$ art. $3^{\circ}$ da Constituição Federal, por sua vez, elege como objetivos fundamentais do Brasil, entre outros, a promoção do bem de todos, "(...) sem preconceitos de origem, raça, sexo, cor, idade e quaisquer outras forma de discriminação". Não poderia ser diferente. Uma sociedade reconhecidamente pluralista não pode comportar qualquer tipo de discriminação, de modo que tudo há de ser feito para expurgar qualquer tipo de preconceito discriminador. O "ser diferente" passa a ser visto - não mais como "ser excluído -, mas como elemento integrante e ativo participante da estrutura social da sociedade política.

É por esta mesma linha de raciocínio que, ao se objetivar no texto constitucional os direitos e garantias fundamentais, estabeleceu-se a igualdade de todos perante lei, "sem distinção de qualquer natureza" (art. $5^{\circ}$, caput), assegurando-se, outrossim, a liberdade de consciência, de crença e de expressão (inciso VI, VIII e IX), sujeitando-se a prática discriminatória às sanções legais (inciso XLI e XLII).

Importante expressão de respeito ao multicultural está no art. $215, \S 1^{\circ}$ da Constituição. Segundo este texto, o "Estado protegerá as manifestações

${ }^{27}$ SARELT, Ingo Wolfgang. A Eficácia dos Direitos Fundamentais, p. 118.

${ }^{28}$ SILVA, José Afonso da. Comentários Contextual à Constituição, p. 40. 
das culturas populares, indígenas e afro-brasileiras, e das de outros grupos participantes do processo civilizatório nacional". É de anotar aqui que a exigência de proteção, importa na exigência de "(...) ações positivas no sentido de defender a existência, a valorização e a difusão dessas culturas especiais". ${ }^{29}$

Em harmonia com tais proteções é que a Constituição também previu, para o processo educacional, o respeito à diversidade cultural (art. 210), tanto assim que pela Lei $n^{\circ} 11.645$, de 10 de março de 2008 passou a se tornar obrigatório, nos estabelecimentos de ensino fundamental e de ensino médio, públicos e privados, o estudo da história e cultura afro-brasileira e indígena (art. 26-A), sendo que o "conteúdo programático a que se refere este artigo incluirá diversos aspectos da história e da cultura que caracterizam a formação da população brasileira, a partir desses dois grupos étnicos, tais como o estudo da história da África e dos africanos, a luta dos negros e dos povos indígenas no Brasil, a cultura negra e indígena brasileira e o negro e o índio na formação da sociedade nacional, resgatando as suas contribuições nas áreas social, econômica e política, pertinentes à história do Brasil" $\left(\S 1^{\circ}\right)$.

Por fim, e agora especificamente em relação aos índios, o art. 231 da Constituição prescreve que "são reconhecidos aos índios sua organização social, costumes, línguas, crenças e tradições, e os direitos originários sobre as terras que tradicionalmente ocupam, competindo à União demarcá-las, proteger e fazer respeitar todos os seus bens".

Deste artigo retro citado percebe-se uma radical mudança de paradigma relativamente às políticas governamentais dirigidas aos índios, com 0 abandono daquela hegemônica visão liberal definidora de direitos (indivíduo, enquanto sujeito de direito, coisa, como bem juridicamente protegido e contrato, a legitimar esta relação entre as pessoas e as coisas), passando agora a vê-los não mais numa perspectiva de objeto de transformação e harmonização com o padrão social nacional, mas, ao contrário, reconheceu a necessidade de proteção destes povos - sob a perspectiva de um direito coletivo - e a garantia de uma convivência harmônica fundada no respeito às culturas que lhe são próprias. ${ }^{30}$

\footnotetext{
${ }^{29}$ SILVA, José Afonso da. Comentários Contextual à Constituição, p. 806. Sobre as políticas de cotas raciais nas Universidades Públicas brasileiras, ver DUARTE, Evandro C. Piza e outros (Orgs.) Cotas raciais no ensino superior. Entre o jurídico e o político. Curitiba: Juruá, 2008. Igualmente interessante no contexto do acesso dos índios às universidades é a coletânea organizada por NOVAK, Maria Simone J. e outros (Orgs.) Educação Superior Indígena no Paraná. Maringá: Editora da UEM, 2010.

${ }^{30}$ Habermas discutindo a questão da igualdade e diferença no contexto dos nacionalismos europeus escreve que nem coexistência, nem assimilação, são modelos adequados, mas sim a construção de uma "Solidariedade entre Diferentes" (Solidarität unter Fremden). (p. 123-124) Igualmente importante é o seu conceito de Nação de Cidadãos (Nation von Staatsbürgern) que não se confunde com origem, língua e histórias comuns. (p. 117-118) HABERMAS, Jürgen. Braucht Europa eine Verfassung? In. Zeit der Übergänge. Frankfurt am Main: Suhrkamp, 2001.
} 
Interessante, a esse respeito, as observações de Marés: "a sobrevivência do multiculturalismo num mundo em que o Estado reconhece, protege e pretende transformar todos os direitos em individuais, é quase impossível. De fato, a construção do Estado contemporâneo e de seu Direito foi marcada pelo individualismo jurídico ou pela transformação de todo titular de direito em um indivíduo. Assim foi feito com as empresas, sociedades e com o próprio Estado; criou-se a ficção de que cada um deles era pessoa, chamada de jurídica ou moral, individual ${ }^{\prime 31}$. Continua o autor paranaense: "assim também foi feito com os povos diferenciados, criando a ficção de que cada povo indígena seria uma individualidade com direitos protegidos. Isto transformava os direitos essencialmente coletivos dos povos em direitos individuais. O Direito contemporâneo, além de individualista, é dicotômico: às pessoas - indivíduos titulares de direitos - corresponde uma coisa - bem jurídico protegido. A legitimidade desta relação se dá por meio de um contrato - acordo entre duas pessoas. É evidente que este esquema jurídico não poderia servir aos povos indígenas da América Latina porque, mesmo que considerasse cada povo uma individualidade de direito, os bens protegidos (os bens que os povos precisam proteger) e sua legitimidade não têm nenhuma relação com a disponibilidade individual e com origem contratual. É por isso que os países latino-americanos sempre buscaram separar o indivíduo indígena de seu povo, assimilando-o à "sociedade nacional" de forma tão profunda que ele deixaria de ser povo diferenciado. O sistema pensou que a assimilação seria possível por meio do trabalho, mas nunca pôde entender que a ideia do trabalho gerador da propriedade não tem relação com as culturas indígenas" ${ }^{\prime 32}$. Por fim, conclui Marés que "tanto lutaram estes povos e tão pequena foi a possibilidade de assimilação que exerceram sobre eles as sociedades envolventes, que o sistema acabou por reconhecer direitos coletivos, que abriram um novo horizonte no reconhecimento dos povos, permitindo aos países se considerarem multiculturais e pluri-étnicos. Estes direitos coletivos extrapolaram os povos indígenas para outros segmentos sociais, de tal forma que acabaram por ter um caráter emancipatório."33

\section{MULTICULTURALISMO, DIREITO À VIDA E INFANTICÍDIO EM COMUNIDADES INDÍGENAS}

Do que já foi dito acima, não se pode ter dúvidas acerca da necessidade de proteção, especialmente mediante ações afirmativas, à diversidade cultural como forma de respeito à dignidade da pessoa humana, ideia esta materializada na Constituição Federal, como se extrai das breves referências feitas.

31 MARÉS, Carlos. Multiculturalismo e Direitos Coletivos. Curitiba, 2001. Disponível em: <http://www.dhnet.org.br/educar/dados/textos/mares_multicult.htm>. Acesso em 16 maio 2010.

${ }^{32}$ MARÉS, Carlos. Multiculturalismo e Direitos Coletivos. Curitiba, 2001.

${ }^{33}$ MARÉS, Carlos. Multiculturalismo e Direitos Coletivos. Curitiba, 2001. 
A questão que agora se coloca é como compatibilizarmos esta necessidade de respeito à diversidade quando esta diversidade, por sua formação cultural própria, conflita com certos valores tidos por universais. Ou seja, o pluralismo, advindo das múltimas formas culturais, pode conviver com o universalismo exigido para certos valores? ${ }^{34}$

Sendo mais objetivo e buscando a compreensão mediante a análise de casos concretos: entre os povos indígenas, a prática do infanticídio é constada em várias de suas comunidades e os motivos que se apresentam são vários. Entre os Yanomami seria a promoção do equilíbrio entre os sexos. Entre os Suruwahá, a deficiência física. Entre os Kaiabi, o nascimento de gêmeos (sendo que a primeira criança é preservada), e assim por diante $^{35}$. Pergunta-se, então: como ficaria, em situações tais, o respeito à cultura indígena se esta cultura estaria, por sua prática, atingindo o maior dos direitos fundamentais, que é a vida?

O tema, em síntese, tem sido analisado sob duas perspectivas teóricas, quais sejam, a do Relativismo Multicultural e a da Universalidade Ética.

O relativismo multicultural seria justamente a corrente que, reconhecendo os valores e práticas específicas de diversas culturas, defende seu respeito e tolerância. Ou seja: "o relativismo cultural, inicialmente desenvolvido por Franz Boas e com base no historicismo de Herder, defende que bem e mal são elementos definidos em cada cultura. E que não há verdades universais visto que não há padrões para se pesar o comportamento humano e compará-lo a outro. Cada cultura pesa a si mesma e julga a si mesma. A mutilação feminina, portanto, não poderia ser avaliada como certa ou errada, mas sim aceita ou rejeitada socialmente, de acordo com o olhar da cultura local sobre este fato social. Para o relativismo radical não há valores

\footnotetext{
${ }^{34}$ Partindo de uma perspectiva que procura dar conteúdo ao conceito de Direitos Humanos, Brugger, ainda que não consiga se desvencilhar de uma visão liberal ocidental, escreve que para uma cultura poder sustentar que defende os direitos humanos, a mesma deve atender a seguinte fórmula: (i) autonomia, consistente na possibilidade da pessoa de se colocar objetivos, desenvolver um plano de vida individual, segui-lo e defendê-lo; (ii) significação, que lembra o fato antropológico, fundamental, de que o desenvolvimento individual, assim como grupal, do povo ou voltado ao gênero do homem e de suas comunidades, é sustentado pela cultura considerada, ou seja, a cultura é a segunda natureza do homem; (iii) responsabilidade, entendida como a) reciprocidade, b) responsabilidade por violações de direitos e c) responsabilidades sociais, para os casos em que se possa exigir dos membros de uma comunidade jurídica que respondam pelo risco de fracasso de planos de vida de indivíduos isolados e de toda a comunidade; (iv) proteção da vida e (v) condução de vida, como elemento conclusivo e centralizador da forma de vida dos direitos humanos, que implica, além da mera possibilidade de sobrevivência e proteção da vida, pelo menos, uma medida mínima de liberdade para um estilo de vida individual. BRUGGER, Winfried. Das Menschenbild der Menschenrechte. In. BYRD, B. Sharon, HRUSCHKA, Joachim e JOERDEN, Jan C. Jahrbuch für Recht und Ethik. Rechtsstaat und Menschenrechte. Band 3 (1995). Uma versão em português do presente artigo encontra-se em Cadernos de Direito e Relações Internacionais da UniBrasil, nº 5, jan./dez. 2005, p. 255-270.

${ }^{35}$ LIDÓRIO, Ronaldo. Índios - Carta Aberta sobre o Infanticídio Indígena - Publicado em 07/09/07. Disponível em: http://www.lideranca.org/cgi-bin/index.cgi?action=viewnews\&id=3161
} 
universais que orientem a humanidade, mas valores particulares que devem ser observados e tolerados. E assim, em sua compreensão de ética, o bem e o mal são relativos aos valores de quem os observa e experimenta"36.

Especificamente em relação aos infanticídios ocorridos, defende-se, segundo este pensamento teórico, a existência, naquelas comunidades indígenas, de uma diferente forma de compreensão acerca do que se entenderia por humano ou nascimento, posto que uma pessoa somente iria adquirir a personalidade ao longo da vida e das relações sociais que estabelecesse. A partir deste ponto de vista, o infanticídio - sob as pré-condições consentidas na comunidade - representaria uma estratégia reprodutiva que, caso não adotada, geraria a impossibilidade de qualquer tipo de socialização ${ }^{37}$.

O Universalismo Ético, por sua vez, partindo do pressuposto da existência de valores comuns à sociedade humana, procura universalizar o pensamento comum dos cidadãos, de modo a superar especificidades culturais. A sociedade humana, em si, possuiria valores universais de moralidade como a dignidade, sobrevivência do grupo e busca pela continuidade da vida individual.

Parece evidente o confronto entre esta teoria universalista e 0 infanticídio aqui tratado. A vida consistiria num valor universal absoluto não sujeito a qualquer relativização.

Para bem ilustrar a problemática prática deste conflito de posições, interessante a referência a um Pedido de Providências ajuizado em 27.04.2009 pelo Ministério Público na Cidade de Manaus ${ }^{38}$ onde se discutiu, em síntese, a situação de uma criança Yanomami, com quadro clínico de hidrocefalia, tuberculose, desnutrição e pneumonia, ter chegado em Manaus para tratamento de saúde, porém, como na cultura Yanomami as mulheres são as encarregadas do trabalho pesado, por isso somente as "saudáveis" são admitidas, a mãe da criança pretendia o retorno da filha à aldeia, a fim de se observar todos os rituais provenientes de sua cultura para o falecimento da menor. O Ministério Público, então, através da ação proposta pretendia garantir a permanência da criança em Manaus, sob tratamento. O pedido foi acolhido, basicamente sob o escoro jurídico do art. 227 da Constituição Federal ${ }^{39}$ e do art. $5^{\circ}$ do Estatuto da Criança e do Adolescente ${ }^{40}$.

\footnotetext{
${ }^{36}$ LIDÓRIO, Ronaldo. Não há morte sem dor - Uma visão antropológica sobre a prática do infanticídio indígena no Brasil. Disponível em: http://instituto.antropos.com.br/index.php?option= com_ content\&task=view\&id=479\&Itemid=69

${ }^{37}$ CŌMISSÃO de direitos humanos e participação legislativa. Senado Federal. Disponível em $<$ http://www.direitoshumanos.etc.br/index.php?option=com_content\&view=article\&id=2483:estudocontesta-criminalizacao-do-infanticidio-indigena\&catid=21:indigenas\&Itemid=165>

${ }^{38}$ Processo n 232/2009 - Disponível em <http://www.diariodeumjuiz.com/downloads/processo2009.232.pdf>

39 “É dever da família, da sociedade e do Estado, assegurar à criança e ao adolescente, com absoluta prioridade, o direito à vida, à saúde, à alimentação, à educação ao lazer à profissionalização, à cultura e à dignidade, ao respeito, à liberdade e à convivência familiar e comunitária, além de colocá-las a salvo de toda forma de negligência, discrimininação, exploração, violência, crueldade e opressão".

40 "Nenhuma criança ou adolescente será objeto de qualquer forma de negligência, discriminação,
} 
Neves investiga o tema aqui tratado quando desenvolve o conceito "transconstitucionalismo" no contexto da relação entre ordens jurídicas estatais e ordens jurídicas locais extraestatais. Trata-se da "problemática relação entre as ordens jurídicas estatais e as ordens extraestatais de coletividades nativas, cujos pressupostos antropológico-culturais não se compatibilizam com o modelo de constitucionalismo do Estado". ${ }^{11}$ São ordens jurídicas "arcaicas que não dispõem de princípios ou regras secundárias de organização e, por conseguinte, não se enquadram no modelo reflexivo do constitucionalismo. A rigor, elas não admitem problemas jurídico-constitucionais de direitos humanos e de limitação jurídica do poder. Ordens normativas dessa espécie (...) exigem, quando entram com colisão com as instituições da ordem jurídica constitucional de um Estado, um 'transconstitucionalismo unilateral' de tolerância e, em certa medida, de aprendizado". 42

O autor pernambucano resgata o histórico da audiência pública realizada no contexto do projeto de Lei 1.057/2007 que procurou criminalizar a prática indígena do infanticídio. Como premissa geral, a criminalização de condutas assentadas na tradição implica verdadeiro genocídio cultural, pois se constitui na destruição da própria comunidade, de suas crenças mais profundas. A antropóloga Rita Laura Segato teve participação ativa na audiência para o esclarecimento do assunto, apontando para a necessidade de um diálogo entre ordens normativas. Ela observou que tinha diante de si a tarefa ingrata de argumentar contra o projeto de lei, mas, ao mesmo tempo, de fazer uma forte aposta na transformação do costume. Na perspectiva do direito à vida, Segato trouxe dados empíricos interessantes de como esse direito está sendo tratado no contexto das comunidades indígenas: entre 2003 e 2005 os Suruahá, índios habitantes do Estado do Amazonas, tiveram 7,6\% das mortes decorrentes de infanticídio e 57,6\% das mortes por suicídio, ou seja, para essa comunidade indígena "a vida só tem sentido se não for marcada por excessivo sofrimento para o indivíduo e a comunidade, se for uma vida tranqüila e amena. (...) O significado atribuído à vida e à morte pelos Suruahá não seria menos digno do que o sentido que Ihes atribui o cristianismo". ${ }^{43}$

Igualmente interessante é a justificativa da prática Yanomami, na qual a mulher tem direito absoluto sobre a vida dos seus recém-nascidos: "o parto ocorre em ambiente natural, fora do contexto da vida social, deixando a opção à mãe: se não toca o bebê nem o levanta em seus braços, deixando-o na terra onde caiu, significa que este não foi acolhido no mundo da cultura e das relações sociais, e que não é, portanto, humano. Dessa forma, não se

exploração, violência, crueldade e opressão, punindo na forma da lei qualquer atentado, por ação ou omissão aos seus direitos fundamentais".

${ }^{41}$ NEVES, Marcelo. Transconstitucionalismo. São Paulo: Martins Fontes, 2009, p. 216.

${ }^{42}$ NEVES, Marcelo. Transconstitucionalismo, p. 216-217.

${ }^{43}$ NEVES, Marcelo. Transconstitucionalismo, p. 225. 
pode dizer que ocorreu, na perspectiva nativa, um homicídio, pois aquele que permaneceu na terra não é uma vida humana". ${ }^{44}$

Essas reflexões mostram a complexidade do tema, que não pode ser tratado a partir de visões unilaterais, que excluam as múltiplas compreensões de vida e existência terrena: "devemos reconhecer o direito de todo povo de dialogar com outros povos a respeito do sofrimento e suas soluções. De compreendê-las, compará-las e decidir sobre qual solução tomar. Devemos reconhecer o direito de todo indivíduo de levantar-se contra os valores culturais experimentados e propor novas alternativas, sobretudo nos casos em que há dano à vida, à dignidade e à subsistência. Devemos reconhecer que nenhuma cultura é estática ou isolada da sociedade humana. E que, pertencente a esta, partilha também os mesmos sonhos e conflitos. Que a ação dialógica, sob o manto da autonomia de cada povo, traz benefícios humanos que não estancam a vivência cultural pois práticas aceitas na atualidade remontam a decisões passadas por critérios próprios ou adquiridos. Que o Estado brasileiro deve tratar o infanticídio indígena de forma ativa, informando e dialogando com as sociedades indígenas em nosso país a respeito das alternativas para solução deste conflito interno, que isente a morte das crianças. Que garanta o direito de vida, criação e dignidade dos indivíduos, independente de seu segmento étnico" ${ }^{45}$.

Parece adequado, pois, um meio termo entre o relativismo e o universalismo cultural. Ainda que tenhamos uma enorme gama de variações culturais, forçoso se faz admitir a existência de valores comuns míninos e, a partir daí, reconhecer então a possibilidade de um processo dialógico multicultural.

Urge ainda exigir do Estado uma postura mais ativa tendente a se repensar conceitos reinantes nas mais diversas comunidades, de modo a se obter conscientização, sem imposição, acerca da necessária preservação de certos valores condicionantes da sobrevivência humana.

\section{REFERÊNCIAS BIBLIOGRÁFICAS}

APPIO, Eduardo. Direito das Minorias. São Paulo: RT, 2009.

BALKIN, Jack M. e SIEGEL, Reva B. The Constitution in 2020. New York: Oxford University Press, 2009.

BASTOS, Celso Ribeiro e MARTINS, Ives Gandra. Comentários à Constituição do Brasil. $1^{\circ}$ Vol. São Paulo: Saraiva, 1988.

BRUGGER, Winfried. Das Menschenbild der Menschenrechte. In. BYRD, B. Sharon, HRUSCHKA, Joachim e JOERDEN, Jan C. Jahrbuch für Recht und Ethik. Rechtsstaat und Menschenrechte. Band 3 (1995). (Em português: A Pessoa Humana dos Direitos Humanos. Cadernos de Direito e Relações Internacionais da UniBrasil", $n^{\circ}$ 5, jan./dez. 2005, p. 255-270.)

\footnotetext{
${ }^{44}$ NEVES, Marcelo. Transconstitucionalismo, p. 225.

${ }^{45}$ LIDÓRIO, Ronaldo. Não Há morte sem dor.
} 
CARDOSO, Clodoaldo Meneguello. Tolerância e seus Limites - Um olhar latino americano sobre a diversidade e desigualdade. São Paulo: Unesp, 2003.

CASTELLS, Manuel. O Poder da Identidade - A Era da Informação. Economia, Sociedade e Cultural. Vol. 2. Trad. Klauss Brandini Gerhardt. São Paulo: Paz e Terra, 2008.

DUARTE, Evandro C. Piza e outros (Orgs.) Cotas Raciais no Ensino Superior. Entre o Jurídico e o Político. Curitiba: Juruá, 2008.

HABERMAS, Jürgen. Die Einbeziehung des Anderen. Frankfurt am Main: Suhrkamp, 1999. Zeit der Übergänge. Frankfurt am Main: Suhrkamp, 2001.

HALL, Stuart. A identidade cultural na pós-modernidade. Trad. Tomaz T. da Silva e Guacira L. Louro. 11. ed. Rio de Janeiro: DP\&A, 2006.

HARTMAN, Gary e outros (Orgs.) Landmark Supreme Court Cases. The Most Influential Decisions of the Supreme Court of the United States. New York: Facts on File Inc., 2004.

LIDÓRIO, Ronaldo. Índios - Carta Aberta sobre o Infanticídio Indígena - Publicado em 07/09/07. Disponível em: http://www.lideranca.org/cgi-bin/index.cgi?action= viewnews \&id=3161

. Não há morte sem dor - Uma visão antropológica sobre a prática do infanticídio indígena no Brasil. Disponível em: http://instituto.antropos.com.br/ index.php?option=com_content\&task=view\&id=479\&/temid=69

MARÉS, Carlos. Multiculturalismo e Direitos Coletivos. Curitiba, 2001. Disponível em: <http://www.dhnet.org.br/educar/dados/textos/mares multicult.htm>. Acesso em 16 maio 2010.

MÜLLER, Friedrich. Métodos de Trabalho do Direito Constitucional. 3. ed. Rio de Janeiro: Renovar, 2005.

NEVES, Marcelo. Transconstitucionalismo. São Paulo: Martins Fontes, 2009.

NOVAIS, Jorge Reis. Contributo para uma Teoria do Estado de Direito: do Estado de Direito liberal ao Estado social e democrático de Direito. Coimbra: Almedina. 2006.

NOVAK, Maria Simone J. e outros (Orgs.) Educação Superior Indígena no Paraná. Maringá: Editora da UEM, 2010.

PACHECO, Marcos Antônio B. Estado Multicultural e Direitos Humanos. Tópica Constitucional dos Direitos Étnicos. São Luis: UFMA/CNPq, 2005.

SABA, Roberto. (Org.) Los Límites de la Democracia. Buenos Aires: Del Puerto, 2005.

SANTOS, Boaventura de Souza (Org.). Reconhecer para Libertar. Os Caminhos do Cosmopolitismo Multicultural. Rio de Janeiro: Civilização Brasileira. 2003.

SARLET, Ingo Wolfgang. A Eficácia dos Direitos Fundamentais. 9. ed. Porto Alegre: Livraria do Advogado, 2008.

SILVA, José Afonso da. Curso de Direito Constitucional. São Paulo: Editora Revista dos Tribunais, 1991.

Comentários Contextual à Constituição. São Paulo: Malheiros Editores, 2008.

SILVA, Larissa Tenfen. O Multiculturalismo e a Política de Reconhecimento de Charles Taylor. NEJ - Vol. 11, n² 2, p. 313-322, jul./dez. 2006.

TAYLOR, Charles. Multiculturalismo. Examinando a Política de Reconhecimento. Lisboa: Instituto Piaget, 1998. 